\title{
Taxonomy and Evolution of Gibbons
}

\author{
THOMAS GEISSMANN
}

Three different data sets of approximately equal size were collected in order to assess their relevance for a reconstruction of gibbon phylogeny with cladistic methods. Set 1 uses characteristics of fur coloration, set 2 consists mainly of morphological and anatomical data, and set 3 consists of vocal data.

Because the fossil history of gibbons is virtually unknown, ${ }^{1,2}$ gibbon evolution can only be reconstructed from a comparative analysis of evolutionarily informative characteristics of modern gibbons and, to some degree, of related primate taxa that can be used as outgroups.

Several studies have tried to reconstruct gibbon phylogeny, using fur coloration, morphological, vocal, or molecular data. ${ }^{3-10}$ Each study produced a different result. As a consequence, the relationships among the various hylobatids are under debate, and even the evolutionary relationships among the major groups of gibbons remain unresolved. ${ }^{11}$

For the present study, three different data sets of approximately equal size were collected in order to assess their relevance for a reconstruction of gibbon phylogeny with cladistic methods. Set 1 uses characteristics of fur coloration, set 2 consists mainly of morphological and anatomical data, and set 3 consists of vocal data.

Thomas Geissmann is at the Institut für Zoologie, Tierärztliche Hochschule Hannover, Bünteweg 17, D-30559 Hannover, Germany (E-mail: thomas.geissmann@ gibbons.de).

Key words: gibbons; taxonomy; evolution; Hylobatidae; phylogeny; vocalizations; fur coloration

Evolutionary Anthropology, Suppl 1:28-31 (2002)

DOI 10.1002/evan.10047

Published online in Wiley InterScience

(www.interscience.wiley.com).

(c) 2002 Wiley-Liss, Inc.

\section{MATERIALS AND METHODS}

Most recent studies agree that there are four distinct groups of gibbons, which are here referred to as genera. Table 1 presents the classification used for the present study. ${ }^{12,13}$

The three large data sets that were analyzed are listed in Table 2. They were analyzed separately and compared with one another using partition-homogeneity tests. ${ }^{14}$

Phylogenetic analyses were conducted with unweighted characters using the PAUP program, version 4.0b3a. ${ }^{14}$ Two types of maximumparsimony trees were generated: a branch-and-bound search of the same data set in PAUP yielded the shortest tree, i.e., a single most parsimonious cladogram, and the bootstrap option of PAUP was used to examine the robustness of internal nodes.

A hypothetical "ancestor" was used as an outgroup. This "ancestor" was assembled using primitive character states wherever they could be reconstructed or plausibly assumed.

The following standard measures were calculated in order to assess the "quality" of trees: consistency index (CI), retention index (RI), and the rescaled consistency index (RC), ${ }^{15,16}$ as well as the number of bootstrap values larger than 50 . The indices basically range from $0-1$, with higher $\mathrm{RC}$ values indicating that characters in the data set are more congruent with each other and the tree.

Mean pairwise distances between taxa (i.e., the sum of their character state differences, divided by the number of characters ${ }^{14}$ ) were calculated with each data set. Three types of distances were compared: 1) distances among subspecies of the same species $(\mathrm{n}=4), 2)$ distances among species of the same genus ( $\mathrm{n}=38$ ), and 3) distances among members belonging to different genera $(n=63)$. In order to increase the sample of subspecies distances, $H$. muelleri was separated into its subspecies (H. m. muelleri, $H$. m. funereus, and $H$. $m$. abbotti) for this part of the analysis.

\section{RESULTS}

Because the three data sets are statistically different $(P=0.01)$ when compared with the partition-homogenetity test, they are not combined in this study.

The trees based on fur coloration (Fig. 1a) strongly contradict all previously published gibbon phylogenies. $^{3-10}$ For instance, members of the lar group appear in the most basal positions of the two shortest trees (not shown). The lar group is not identified as a monophyletic group: Hylobates klossii is shown as the sister taxon of the siamang (Symphalangus syndactylus), obviously because both gibbons are completely black. In contrast, most previously published phylogenies identify $H$. klossii as a member of the genus Hylobates, whereas the siamang is placed in the genus Symphalangus.

The trees based on "noncommunicatory" data (Fig. 1b) resemble the trees of earlier studies far more closely. The data set has a relatively low resolution because of the many missing values in the data matrix. Many of the anatomical data were collected during very early studies, when several gibbon taxa were simply not known. As a result of the empty cells in the matrix, there is not one single most parsimonious tree, but an ensemble of 117 shortest trees. 
TABLE 1. Main Divisions of Genus Hylobates ${ }^{a}$

\begin{tabular}{|c|c|c|c|c|}
\hline Genus & $\begin{array}{l}\text { Diploid Number } \\
\text { of Chromosomes }\end{array}$ & $\begin{array}{l}\text { Other Division } \\
\text { Names }\end{array}$ & Species & English-Language Name \\
\hline Hylobates & 44 & lar group & $\begin{array}{l}\text { H. agilis } \\
\text { H. klossii } \\
\text { H. lar } \\
\text { H. moloch } \\
\text { H. muelleric } \\
\text { H. pileatus }\end{array}$ & $\begin{array}{l}\text { Agile gibbon } \\
\text { Kloss's gibbon } \\
\text { White-handed gibbon } \\
\text { Silvery gibbon } \\
\text { Müller's gibbon } \\
\text { Pileated gibbon }\end{array}$ \\
\hline Bunopithecus & 38 & & B. hoolock & Hoolock \\
\hline Nomascus & 52 & $\begin{array}{l}\text { concolor group, } \\
\text { crested gibbons }\end{array}$ & $\begin{array}{l}\text { N. concolor } \\
\text { N. sp. cf. nasutus } \\
\text { N. gabriellae } \\
\text { N. leucogenys }\end{array}$ & $\begin{array}{l}\text { Western black crested gibbon } \\
\text { Eastern black crested gibbon } \\
\text { Yellow-cheeked crested gibbon } \\
\text { White-cheeked crested gibbon }\end{array}$ \\
\hline Symphalangus & 50 & & S. syndactylus & Siamang \\
\hline
\end{tabular}

a Raising the four main groups of gibbons to genus rank follows the consensus reached at the workshop "Primate Taxonomy for the New Millennium" (February 25-29, 2000, Orlando, Florida), to be presented in a future publication, and reference 20.

b Including $H$. agilis albibarbis.

c Including $H$. muelleri abbotti and $H$. muelleri funereus.

d Including N. leucogenys siki.

The trees based on vocal characteristics (Fig. 1c) are similar to those of data set 2. Bunopithecus hoolock appears in an unusually basal position in the tree, however, because of its many apparently primitive vocal characteristics. Hylobates klossii is identified as the sister taxon of $H$. moloch.

The various standard measures calculated in order to assess the "quality" of trees are shown in Table 2 (bootstrap values, CI, RI, and RC). Data set 1 scores distinctly worse in all variables than the other two data sets. The difference between data sets 2 and 3 is less distinct in these variables. Nevertheless, data set 3 has higher values in all of these variables (especially in bootstrap values) than set 2 , indicat- ing that particularly "good" trees are generated with vocal data.

The mean pairwise distances between gibbon taxa are shown in Figure 2. Fur coloration data are able to differentiate not only between species and genera, but also between subspecies. Both the range and standard deviation of the distances are extremely large, however, and show a broad overlap among different systematic levels. This means that differences in fur coloration provide little information on the genetic distance between any two taxa. Two subspecies may be more different in fur coloration than members of two different genera.

"Noncommunicatory" data, on the other hand, do not differentiate well between subspecies, and the standard deviations for subspecies and species overlap. These data differentiate between some, but not all, species. The pairwise differences between members of different genera are distinctly greater than those between species, and standard deviations for species and genera do not overlap.

The vocal data produce similar results to the "noncommunicatory" data. This data set does not differentiate between subspecies at all, but differentiates well between species and genera. Standard deviations of subspecies, species, or genera do not overlap.

The three data sets also differ in the species groups they support (Table 2).

TABLE 2. Various Parameters of Trees in Figure 1, and Topologies of Gibbon Taxa Supported by These Trees ${ }^{a}$

\begin{tabular}{|c|c|c|c|c|c|c|}
\hline \multirow{2}{*}{$\begin{array}{l}\text { Data Set } \\
\text { Number of Characters } \\
\text { Type of Tree }\end{array}$} & \multicolumn{2}{|c|}{$\begin{array}{l}\text { Set } 1 \\
37\end{array}$} & \multicolumn{2}{|c|}{$\begin{array}{c}\text { Set } 2 \\
34\end{array}$} & \multicolumn{2}{|c|}{$\begin{array}{c}\text { Set } 3 \\
34\end{array}$} \\
\hline & $\mathbf{s}$ & B & $\mathbf{s}$ & B & $\mathbf{s}$ & B \\
\hline $\begin{array}{l}\text { Tree length } \\
\text { Number of bootstrap values above } 50\end{array}$ & 158 & $\begin{array}{r}191 \\
5\end{array}$ & 73 & $\begin{array}{r}78 \\
5\end{array}$ & 88 & $\begin{array}{l}90 \\
10\end{array}$ \\
\hline Number of shortest trees & 2 & & 117 & & 1 & \\
\hline Consistency index (Cl) & 0.49 & 0.41 & 0.66 & 0.62 & 0.67 & 0.66 \\
\hline Retention index (Rl) & 0.63 & 0.47 & 0.80 & 0.77 & 0.81 & 0.80 \\
\hline Rescaled consistency index (RC) & 0.31 & 0.19 & 0.53 & 0.47 & 0.54 & 0.52 \\
\hline Monophyly of agilis and albibarbis & - & - & - & - & + & + \\
\hline Monophyly of concolor group & + & + & + & + & + & + \\
\hline $\begin{array}{l}\text { Monophyly of lar group (44-chromosome } \\
\text { gibbons) }\end{array}$ & - & - & + & + & + & + \\
\hline H. hoolock as sister group of lar group & - & - & + & + & - & - \\
\hline H. klossii sister of all other members of lar & - & - & - & - & - & - \\
\hline
\end{tabular}

a et 1, fur coloration data; Set 2, "noncommunicatory" data; Set 3, vocal data. S, shortest tree; B, Bootstrap 50\% majority-rule consensus tree; +, supported; -, not supported. 

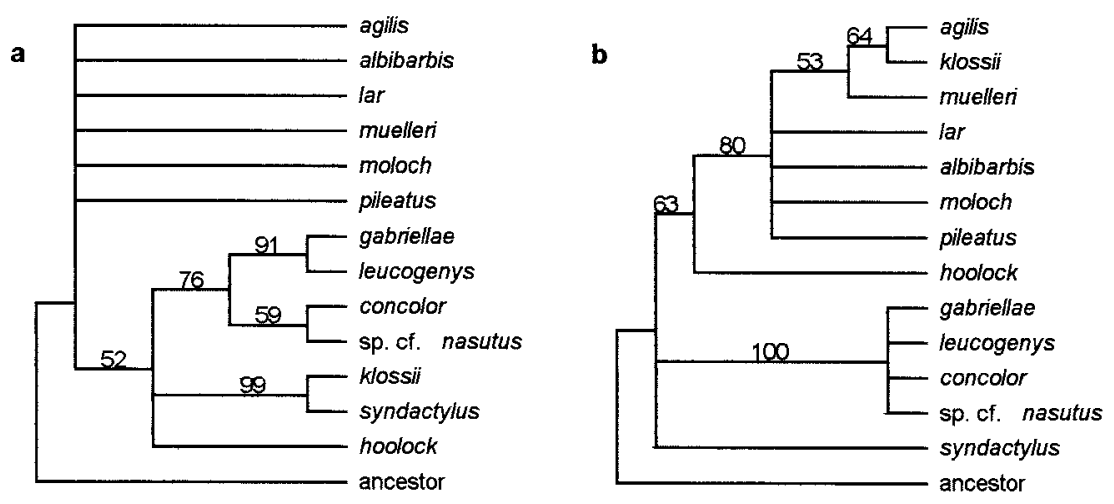

but of the data sets under study, the vocal data produce the most reliable phylogeny. The trees generated using vocal data suggest that:

Gibbons of the genus Hylobates (lar group) and the genus Nomascus (crested gibbons or concolor group) are each monophyletic groups. There is weak support for a sister-group relationship between the concolor and lar groups.

Hylobates klossii is neither the sister taxon of the siamang (Symphalangus syndactylus), as suggested by some early studies, ${ }^{17,18}$ nor the sister taxon or the most basal group of the lar group, in contrast to many previous studies. ${ }^{4-6,9,19}$ This species is a fully integrated member of the lar group, ${ }^{7}$ and apparently the sister taxon of $H$. moloch. The same conclusion was independently reached by a study using a much smaller set of vocal characteristics (including degree of sex-specificity of the vocal repertoire, occurrence of solo songs, and preference for a specific time of day for song production). ${ }^{10}$

Bunopithecus hoolock may be more basal than previously believed. Most earlier studies recnot supporting $H$. klossii as the sister taxon to the other members of the lar group.

\section{DISCUSSION}

A cladistic analysis suggests that the tempo of evolutionary change differs among the data sets under study, similar to DNA sequences derived from different parts of the genome. Fur coloration characters appear to change considerably faster than either "noncommunicatory” or vocal characters.

The three data sets produce different results, and each set appears to be suited to the analysis of different levels of resolution within the hylobatid radiation. Fur coloration characteristics appear to provide little information for a gibbon phylogeny, but may be valuable tools for subspecies identification, in contrast to most characters of the other two data sets. In addition, many fur coloration characters

differ among individuals of the same taxon (polymorphisms).

"Noncommunicatory" data would seem to be much better suited for reconstructing the gibbon phylogeny, ognized this species as the sister

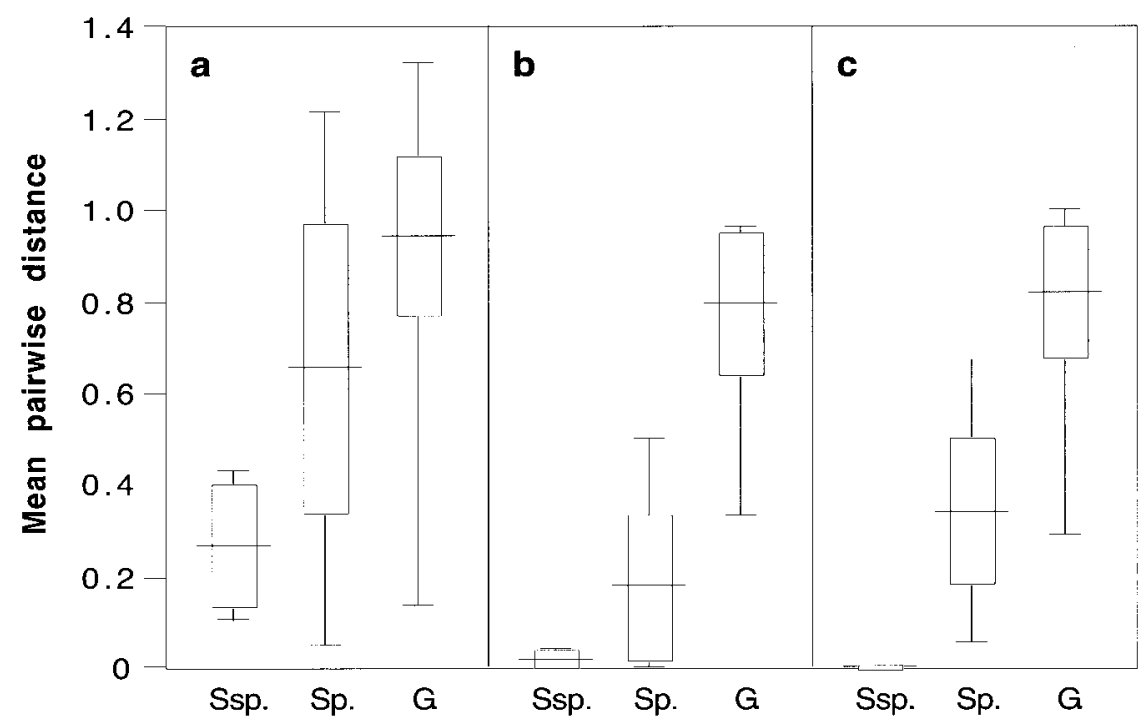

Figure 2. Pairwise character differences between (left to right) different subspecies (Ssp.) of the same species, species (Sp.) of the same genus, and genera (G.) of the same genus. a: Fur coloration data. b: "Noncommunicatory" data. c: Vocal data. Each boxplot shows mean value (horizontal line through box), standard deviation (box), and range ("whiskers"). 
taxon to the lar group, 4,5,9 whereas a more basal position has only rarely been suggested. $6,10,21$

The radiation of the four genera and of the species within the genera is not reliably resolved with these preliminary results. In future studies, the reliability of the trees may be improved by integrating data from several data sets, by weighting the characters, and by supplementing the missing variables in data set 2 .

\section{REFERENCES}

1. Fleagle JG. 1999. Primate adaptation and evolution. San Diego and London: Academic Press.

2. Geissmann T. 1993. Evolution of communication in gibbons (Hylobatidae). Ph.D. thesis, University of Zürich, Zürich, Switzerland.

3. Groves CP. 1972. Systematics and phylogeny of gibbons. In: Rumbaugh DM, editor. Gibbon and siamang, volume 1. Basel and New York: Karger. p 1-89.

4. Chivers DJ. 1977. The lesser apes. In: Prince Rainier III of Monaco, Bourne GH, editors. Primate conservation. New York: Academic Press. p 539-598.
5. Haimoff EH, Chivers DJ, Gittins SP, Whitten AJ. 1982. A phylogeny of gibbons (Hylobates spp.) based on morphological and behavioural characters. Folia Primatol (Basel) 39:213-237.

6. Creel N, Preuschoft H. 1984. Systematics of the lesser apes: a quantitative taxonomic analysis of craniometric and other variables. In Preuschoft H, Chivers DJ, Brockelman WY, Creel $\mathrm{N}$, editors. The lesser apes. Evolutionary and behavioural biology. Edinburgh: Edinburgh University Press. p 562-613.

7. Garza JC, Woodruff DS. 1992. A phylogenetic study of the gibbons (Hylobates) using DNA obtained non-invasively from hair. Mol Phylogenet Evol 1:202-210.

8. Hayashi S, Hayasaka K, Takenaka O, Horai S. 1995. Molecular phylogeny of gibbons inferred from mitochondrial DNA sequences: preliminary report. J Mol Evol 41:359-365.

9. Purvis A. 1995. A composite estimate of primate phylogeny. Philos Trans R Soc Lond [Biol] 348:405-421.

10. Geissmann T. 2002. Duet-splitting and the evolution of gibbon songs. Biol Rev 77:57-76.

11. Hall LM, Jones DS, Wood BA. 1998. Evolution of the gibbon subgenera inferred from cytochrome $b$ DNA sequence data. Mol Phylogenet Evol 10:281-286.

12. Geissmann T. 1995. Gibbon systematics and species identification. Int Zoo News 42:467-501.

13. Geissmann T. 1997. New sounds from the crested gibbons (Hylobates concolor group): first results of a systematic revision. In: Zissler D, editor. Verhandlungen der Deutschen Zoo- logischen Gesellschaft: Kurzpublikationenshort communications, 90. Jahresversammlung 1997 in Mainz. Stuttgart: Gustav Fischer. p 170. 14. Swofford DL. 2000. PAUP*. Phylogenetic analysis using parsimony (*and other methods). Version 4. Sunderland, MA: Sinauer Associates.

15. Kitching IJ, Forey PL, Humphries CJ, Williams DM. 1998. Cladistics. Second edition. The theory and practice of parsimony analysis. Oxford and New York: Oxford University Press.

16. Maddison WP, Maddison DR 1992. MacClade: analysis of phylogeny and character evolution. Version 3.0. Sunderland, MA: Sinauer Associates.

17. Elliot DG. 1913. A review of the primates, volume 3: Anthropoidea, Miopithecus to Pan. New York: American Museum of Natural History.

18. Miller GS Jr. 1903. Seventy new Malayan mammals. Smithson Misc Coll 45:1-73.

19. Schultz AH. 1933. Observations on the growth, classification and evolutionary specialization of gibbons and siamangs. Hum Biol 5:212-255, 385-428.

20. Roos C, Geissmann I. 2001. Molecular phylogeny of the major hylobatid divisions. Mol Phylogenet Evol 19:486-494.

21. Zehr SM. 1999. A nuclear and mitochondrial phylogeny of the lesser apes (Primates, genus Hylobates). $\mathrm{PhD}$ thesis, Harvard University, Cambridge, MA. 